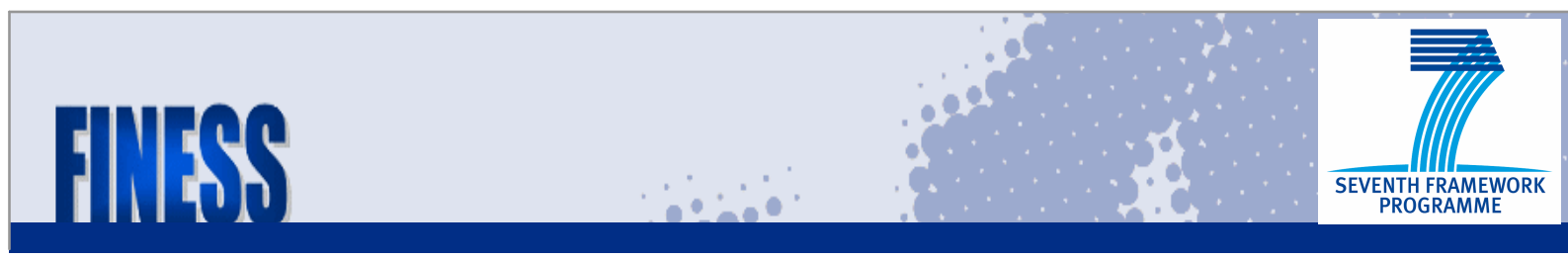

Project funded under the Socio-economic Sciences and Humanities

Working Paper D.1.1b

\title{
European Financial Market Integration: A Closer \\ Look at Government Bonds in Eurozone Countries
}

Sebastian Weber

February 2009 


\title{
European Financial Market Integration: A Closer Look at Government Bonds in Eurozone Countries
}

\author{
Sebastian Weber ${ }^{1}$
}

\begin{abstract}
The European Union made a number of steps not least of them the introduction of a common currency to foster the integration of the European financial markets. A number of papers have tried to gauge the degree of integration for various financial markets looking at the convergence of interest rates. A common finding is that government bond markets are quite well integrated. In this paper stochastic Kernel density estimates are used to take a closer look at the dynamics that drive the process of interest rate convergence. The main finding is that countries with large initial deviations from the mean interest rate do indeed converge. Interestingly the candidates least suspected namely the countries initially with interest rates at the mean level show a pattern of slight divergence.
\end{abstract}

Keywords: Financial markets integration, euro area government bonds, stochastic Kerneldensity estimates

JEL Classification: C23, E36, G15

\footnotetext{
${ }^{1}$ German Instiute for Economic Research (DIW Berlin), Mohrenstr. 58, D-10117 Berlin, sweber@diw.de. The research leading to these results has received funding from the European Community's Seventh Framework Programme (FP7/2007-2013) under grant agreement number 217266. The author likes to thank Ulrich Fritsche, Wendy Carlin and the discussants of the FINESS Steering Group meeting for helpful advice and comments.
} 


\section{Introduction}

That the integration of markets leads to more efficiency through more competition is one of the mantras of economists. An especially important role is assigned to financial markets. As an intermediary between savers and lenders financial markets are important for investments and therefore for overall economic growth. A better integration of financial markets should lead to lower wedges between the rates that savers receive and the rates that lenders have to pay leading to lower interest rates in general and therefore higher investment. Through better diversification integrated financial markets also reduce the systematic risk of financial investments $^{2}$.

The European Union has made a lot of steps to ensure the integration of the goods as well as the financial markets between member states. A first step was made in 1973 by allowing the freedom of establishment and with the First Banking Directive in 1977. The Single European Act in 1986 followed as well as the Second Banking Directive in 1989 (Buch 2000). The greatest impact was the introduction of the Euro in 1999 as book money and in 2002 as hard cash thus eliminating the exchange rate risk (Jappelli and Pagano 2008).

In general market integration can be defined as "the opening and development of trade between heretofore autonomous markets and their integration into a single operative entity" (Jacks 2000, p 2). Absent of transaction costs homogenous goods should be traded at the same price in fully integrated markets. This is normally referred to as the Law of One Price (LOOP). One way to measure market integration is therefore to look at the convergence of prices in different markets. Since government bonds are a fairly homogenous good especially among the EMU countries with very similar risk structures and transactions costs for financial

\footnotetext{
${ }^{2}$ For a general overview see e.g. Pagano (1993).
} 
transactions are nowadays low due to the Internet one should see the integration of financial markets in a convergence of government bond yields.

A vast amount of literature is trying to gauge the degree of financial markets integration in Europe. Two standard approaches are used. The first one follows Feldstein and Horrioka (1980) in analyzing the connection between national savings and national investment. In fully integrated financial markets the level of national investment should be independent of national savings. The second approach focuses on the interest parity condition and tests if LOOP is satisfied. When standard methodology is used to estimate convergence like $\beta$ convergence one might fall into the pit of Galton's Fallacy (Friedman 1992 and Quah 1993). This could lead to a negative and significant sign for the $\beta$-coefficient while the underlying data does not show a pattern of convergence. For example a country A initially starts with an interest rate of $10 \%$ and another country B has an interest rate of 5\%. Ten periods later A has an interest rate of $5 \%$ and $\mathrm{B}$ of $10 \%$. This would lead to a negative coefficient for the initial level of the interest rate implying $\beta$-convergence. A better way of measuring convergence is the concept of $\sigma$-convergence where a falling standard deviation is interpreted as convergence. Still this measure might not show the whole picture. The same level of standard deviation can be associated with countries continually fluctuating around the mean being sometimes above sometimes below mean. It could as well mean that countries are persistently above or below the mean. The last case would imply that convergence is less distinct than in the first case.

Adam et al. (2001) estimate $\beta$-convergence using data starting in January 1995 to September 2001 for the Eurozone plus Denmark. They do indeed find convergence. Since $\sigma$-convergence is the further reaching concept i.e. $\beta$-convergence is a necessary but not sufficient condition for $\sigma$-convergence Adam et al. also investigate the change in the standard deviation. The standard deviation for the bond spread relative to Germany decreased in 1999 to $1 / 4$ of the 
initial level in 1995. They conclude that "Overall, convergence is almost achieved in this [government bond] market" (Adam et al. 2002, p. 2).

Pagano and von Thadden (2004, p. 20) show descriptively that yield differentials have not disappeared completely in the Eurozone despite dramatic convergence. They demonstrate that the yield differentials and the credit ratings of the countries are highly correlated which implies that the yield differentials are caused by risk premiums.

Three studies (Codogno et al. 2003, Geyer et al. 2004 and Favero et al. 2005) look closer at the relationship between the yield differentials and possible explanatory factors. All three studies find that the differential is driven by a common risk factor and not by country specific liquidity differences.

Baele et al. (2004) find that the change in government bond yields for each member of the EMU is driven mostly by common shocks and not by idiosyncratic (country specific) shocks. In 1997 about $50 \%$ of the change was driven by common shocks while in $200297 \%$ of the change could be explained by common shocks.

Overall the literature shows a significant amount of convergence for government bonds in the Eurozone. A closer look at the data still reveals a considerable amount of differences between the government bond yields. Therefore a closer look at the convergence process seems appropriate.

In this paper an alternative measure of convergence is used to take a closer look at the convergence of European financial markets which should mitigate Galton's Fallacy. The method employed in this paper is the so called stochastic Kernel-density estimation. With this method probabilities for being in a certain state in period $t+n$ conditional on the initial state in $t$ can be estimated. Absolute convergence would be achieved when regardless of the initial state the probability for jumping to the mean interest rate is equal to one. 
The rest of the paper proceeds as follows. In the next section the methodology for calculating stochastic Kernel-density estimators is explained. The results for the government bond market are presented in Section three. Section four concludes.

\section{Stochastic Kernel-density estimation ${ }^{3}$}

If $\mathbf{X}=X\left\{X_{t}\right\}_{t \in \mathbb{N}}$ is a continuous state Markov chain with $X_{t}$ having a distribution function $\phi_{t}$ then $\mathbf{X}$ satisfies:

$$
\operatorname{Pr}\left(X_{t+\tau} \in \mathbf{A} \mid X_{j}, j \leq t ; X_{t}=x\right)=P^{\tau}(x, A)
$$

with $\mathbf{A} \subseteq \mathbf{E} \subseteq \mathbb{R}$ and $\mathbf{E}$ being the state space of $\mathbf{X} . P^{\tau}$ is a conditional distribution also called stochastic Kernel (Stockey et al. 1989, p. 226). Equation (1) states that the probability for being in a certain state which is an element of the subset $\mathbf{A}$ in period $t+\tau$ conditional on being in state $x$ in period $t$ is independent of all previous periods which is the Markovian property. The probability is also independent of $t$ which is the time homogeneity property. $P^{\tau}$ is than a mapping of $\phi_{t}$ into $\phi_{t+\tau}$ (Quah 1997):

$$
\phi_{t+\tau}=\int_{E} P^{\tau}(x, A) \phi_{t}(d x)
$$

This can also be written in terms of density functions:

$$
f_{t+\tau}(y)=\int_{E} f_{\tau}(y \mid x) f_{t}(x) d x=\int_{E} \frac{f_{\tau}(y, x)}{f_{t}(x)} f_{t}(x) d x
$$

where $f_{t}(x)$ is the density function of $\phi_{t}, f_{\tau}(y \mid x)$ is the density function for $P^{\tau}$ and $f_{\tau}(y, x)$ is the joint distribution of $y$ and $x$. Equation (3) shows that the density function for

\footnotetext{
${ }^{3}$ The following presentation of stochastic Kernel-density estimation is based on the exposition in Fotopouos (2006).
} 
$P^{\tau}$ can be calculated by estimating the expression $\frac{f(y, x)}{f(x)}$. For estimating the joint density a product Gaussian kernel ${ }^{4}$ will be used:

$$
f(y, x)=\frac{1}{n} \sum_{i=1}^{n} \frac{1}{h_{x} \sqrt{2 \pi}} e^{-0.5\left(\frac{x-x_{i}}{h_{x}}\right)^{2}} \frac{1}{h_{y} \sqrt{2 \pi}} e^{-0.5\left(\frac{y-y_{i}}{h_{y}}\right)^{2}}
$$

which implies that:

$$
f(x)=\int_{-\infty}^{\infty} f(y, x) d y=\frac{1}{n} \sum_{i=1}^{n} \frac{1}{h_{x} \sqrt{2 \pi}} e^{-0.5\left(\frac{x-x_{i}}{h_{x}}\right)^{2}}
$$

which is simply the univariate Gaussian Kernel. $h_{i}$ represents the bandwidth. The bandwidth is calculated according to Silverman (1986) and minimizes the mean integrated square error if the data were Gaussian and a Gaussian Kernel was used.

The stochastic Kernel-density estimates the law of motion for the process under scrutiny. As such it is a summary of the first and last period and the transition of the observed objects between during the periods. In contrast $\beta$-convergence only looks at the transition relative to the first period without looking at the end result. The further reaching $\sigma$-convergence analyses all observed periods but only in terms of standard deviations and as such is only using a part of the available information in the data. Stochastic Kernel-density estimates do explore all available information of the transition process. The drawback is that only a graphical analysis can be conducted without any formal testing. This is the usual target conflict in statistics: The raw data contains too much information so it has to be summarized. If it is summarized to much important patterns might be neglected. In this sense stochastic Kernel-density is one step below the traditional convergence concepts in information summarization leading to

\footnotetext{
${ }^{4}$ For a discussion of the properties of the product Gaussian kernel see e.g. Wand and Jones (1995) or Pagan and Ullah (1999).
} 
more but also more difficult to interpret information. As such Kernel-density estimates are not a replacement but a complement of traditional convergence concepts.

\section{Empirical Results}

The data used in the following analyze is the long-term government bond yield obtained from the International Monetary Funds' International Financial Statistics (IFS). Monthly data is used for the period January 1971 to September 2007. The initial period (January 1971) is chosen since this date should be fairly in advance to any measures taken to integrate European financial markets. Countries included in the data set are Austria, Belgium, France, Germany, Ireland, Italy, Luxembourg, Netherlands and Portugal. For other member states of the Eurozone the time series were not long enough. Table 1 summarizes some descriptive data for different time periods.

\section{- insert Table 1 -}

The periods prior to the monetary union are quite similar the mean interest rate is quite high with a large standard deviation. While the maximum interest rate is varying with the mean interest rate the minimum interest rate is fairly stable during all periods prior to the EMU. After fixing the exchange rates in 1998 the mean and the standard deviation drop significantly. The minimum interest rate drops a little bit but all in all it appears as if interest rates did converge to the minimum interest rate instead of a convergence to the mean rate. After the introduction of cash in 2002 the standard deviation increases again while interest rates decrease further.

\section{- insert Figure 1 -}

In Figure 1 the Kernel density estimate (5) is shown for the initial period. It becomes apparent that for the initial period divergence is quite common. There are three clusters. The largest concentration of countries is already at the mean interest rate - about 8 percent - located. 
Another concentration is about $1 \frac{1}{2} 2$ standard deviation below the mean interest rate while another group is located at about 2 standard deviations above the mean interest rate.

- insert Figure 2 -

The one year ahead stochastic density estimate is presented in Figure 2. In the left plot the $x$ axis measures the initial period, the $y$-axis is the 12 month ahead level and at the $z$-axis the estimated density is shown. This time four clusters are present. The first set of countries (D) has below average interest rates and stays at this level. The second set (A) has above average interest rates and also stays at this level. The set of countries initially at the mean interest rate seems to diverge slightly as can be seen from the double peek (B and C) in the middle of the graph. Some of the countries stay at the average interest rate while another set of countries moves towards the set of countries with lower than average interest rates. This pattern is also apparent when looking at the counter plot in the right part of Figure 2.

- insert Figure 3 -

To measure the impact of the EMU on the integration of financial markets Figure 3 shows the stochastic Kernel-density estimate for January 1999 as the final year ${ }^{5}$. The $y$-axis again represents the state space for the final year ${ }^{6}$. It can be seen that the two clusters above and below the average interest rate (A and $\mathrm{D})$ showed a marked tendency to converge also to a

\footnotetext{
${ }^{5}$ The base year is held constant to make a comparison between different graphs easier. With a changing base year a countries position in the starting distribution could also change. In that case an observation below the mean interest rate in two different graphs might not represent the same country creating the same pitfall as the $\sigma$ convergence concept. As a check for robustness of the results different base years were chosen without altering the core results. The estimates are available upon request.

${ }^{6}$ One could choose the same scaling fort he $\mathrm{y}$-axis as for the $\mathrm{x}$-axis. This would show the decline in the standard deviation apparent from Table 1. It would on the other hand make an interpretation of the graph even harder since the probability mountain would become fairly small in comparison to the overall graph. Therefore the different scales are chosen.
} 
level that is higher than the level to which most of the other countries do converge. It also becomes clear that the countries initially at the mean interest rate do not converge as nicely. The mountain representing this group has a single peak $(\mathrm{C})$ at about $3.6 \%$ but is quite broad with another small peak (B) at about 3.9\% - the rate to which the above and below average countries tend. This implies that countries initially at the mean interest rate actually diverge somewhat also on a fairly low level when looking at the absolute value. Compared to Figure 2 this tendency to diverge is far less pronounced so that one can conclude that the EMU did indeed lead to convergence albeit not a perfect on. In Figure the right part of Figure 3 the contour plot shows this tendency from a different perspective. Figure 4 shows the Kerneldensity estimate for the transition to period January 2002 after the introduction of the hard cash.

- insert Figure 4 -

The divergence of the initially at the mean interest rate group becomes even stronger after the introduction of the Euro as hard cash. The mountain representing this group is now multi peaked (B, C and D) and broader than in Figure 3. Figure 5 pictures the most recent stochastic Kernel-density estimates i.e. with September 2007 as final period. The divergence of the mean interest group is even more distinct than in the previous graphs. While the below and above average groups (A and D) still show a high degree of convergence, i.e. a tendency towards the mean interest rate, the middle group has two distinctive peaks (B and C) well above and below the mean.

$$
\text { - insert Figure } 5 \text { - }
$$

It should be noted that this tendency for divergence in recent years is on a fairly low absolute level. Compared with the initial range of bond yields from 5 to $11 \%$ the range in 2007 from 4.2 to $4.7 \%$ is a significant convergence of interest rates. But convergence up to the year 1999 was on a better way than the most recent development. Given this tendency to diverge 
somewhat one might look at the long term prospect if this tendency to diverge would persist.

To this end the ergodic distribution:

$$
f_{\infty}(y)=\int_{E} f_{\infty}(y \mid x) f_{t}(x) d x
$$

can be calculated (Johnson 2000, 2005). To this end the average one month transition probabilities for the year 2007 are calculated. For the resulting transition matrix $P$ the solution to

$$
\phi=\phi P
$$

is the ergodic distribution $\phi$. The distribution is pictured in Figure 6.

$$
\text { - insert Figure 6- }
$$

As can be seen the long run dynamics - if the law of motion of the year 2007 would govern the movement of interest rates infinitely - would indeed lead to a twin peaked distribution. The difference between the tow peaks is only 0.3 percentage points so the level of long term divergence would be very small.

\section{Conclusions}

Using stochastic Kernel-density estimates it was shown that the integration of European financial markets has made considerable progress when measured by long-term government bond yields. Overall the picture of convergence found in the literature could be confirmed. The process of convergence is mainly driven by countries that had initially large deviations from the mean interest rate. Those countries converged to the mean interest rate with the introduction of the Euro and afterwards showed no tendency to diverge again.

Interestingly the countries initially at the mean interest rate level show very distinctive patterns of divergence. This pattern can be seen before the freedom of establishment was allowed (1973) or the First Banking directive was enacted (1977). The tendency to diverge is somewhat mitigated during the period of the Euro introduction but is becoming stronger 
afterwards. The most recent estimates than show a tendency to diverge for this group of countries that is as strong as the pattern for the year 1971/72. One should keep in mind that the pattern is as strong as in the initial period but that the distribution itself is much slimmer than the initial distribution. This means that the divergence takes place on a quite low level. The long-run equilibrium distribution shows that the absolute level of divergence would be quite low so that there appears to be no immanent need for policy measures.

What could not be addressed in this paper is the question why this divergence occurs. One usually expects that countries initially far away from the mean would take some time for convergence and might therefore cause patterns of divergence. Especially the high interest rate countries would be suspects for patterns of divergence since high interest rates suggest some degree of financial instability. Given that the nominal interest rate is made up of the real interest rate, inflation expectations, a liquidity premium and a risk premium one has four candidates that could explain this slight divergence. This leaves room for further research addressing the causes for the divergence. 


\section{References}

Adam, K., T. Jappelli, A. Menichini, M. Padula and M. Pagano (2002): Analyze, Compare, and Apply Alternative Indicators and Monitoring Methodologies to Measure the Evolution of Capital Market Integration in the European Union, Report to the European Commission, Directorate General for Internal Affairs.

Baele, L., A. Ferrando, P. Hördahl, E. Krylova and C. Monnet (2004): Measuring Financial Integration in the Euro Area, ECB Occasional Paper Series No. 14.

Buch, C. M. (2000): Financial Market Integration in the US: Lessons for Europe?, Kiel Working Paper No. 1004.

Codogno, L., C. Favero and A. Missale (2003): Government Bond Spreads, Economic Policy, Vol. 18, 503-532.

Favero, C., M. Pagano and E.-L. von Thadden (2005): Valuation, Liquidity and Risk in Government Bond Markets, IGIER Working Paper No. 281.

Fotopoulos, G. (2006): Nonparametric Analysis of Regional Income Dynamics: The Case of Greece, Economic Letters, Vol. 91, 450-457.

Friedman, M. (1992): Do Old Fallacies Ever Die?, Journal of Economic Literature, Vol. 30, 2129-2132.

Feldstein, M. and C. Horioka (1980): Domestic Savings and International Capital Flows, The Economic Journal, Vol. 90, 314-329.

Geyer, A., S. Kossmeier and S. Pichler (2004): Measuring Systematic Risk in EMU Government Yield Spreads, Review of Finance, Vol. 8, 171-197.

Jacks, D. (2000): Market Integration in the North and Baltic Seas, 1500-1800, LSE Working Paper No. 55/00.

Jappeli, T. and M. Pagano (2008): Financial Market Integration under EMU, CSEF Working Papers No. 197. 
Johnson, P. A. (2000): A Nonparametric Analysis of Income Convergence across the US States, Economic Letters, Vol. 69, 219-223.

Johnson, P. A. (2005): A Continuous State Space Approach to "Convergence by Parts", Economic Letters, Vol. 86, 317-321.

Pagan, A. and A. Ullah (1999): Nonparametric Econometrics, Cambridge University Press, Cambridge.

Pagano, M. (1993): Financial markets and growth: An overview, European Economic Review, Vol. 37, 613-622.

Pagano, M. and E.-L. von Thadden (2004a): The European Bond Markets under EMU, CSEF Working Paper No. 126.

Quah, D. (1993): Galton's Fallacy and the Tests of Convergence Hypothesis, The Scandinavian Journal of Economics, Vol. 95, 427-443.

Quah, D. (1997): Empirics of Growth and Distribution: Stratification, Polarization, and Convergence, Journal of Economic Growth, Vol. 2, 27-59.

Silverman, B. W. (1986): Density Estimation for Statistics and Data Analysis, Monographs on Statistics and Applied Probability, Vol. 26, Chapman and Hall, London.

Stockey, N. L., R. E. Lucas and E. C. Prescott (1989): Recursive Methods in Economic Dynamics, Harvard University Press, Cambridge Massachusetts.

Wand, M. P. and M. C. Jones (1995): Kernel Smoothing, Monographs on Statistics and Applied Probability, Vol. 60, Chapman and Hall, London. 


\section{Appendix}

Figure 1: Kernel density estimate for the initial period.

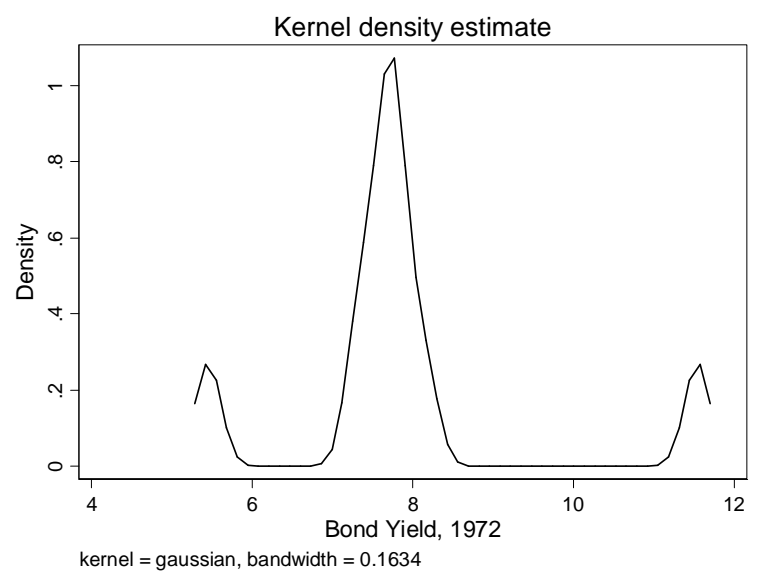


Figure 2: One year ahead stochastic Kernel estimate.
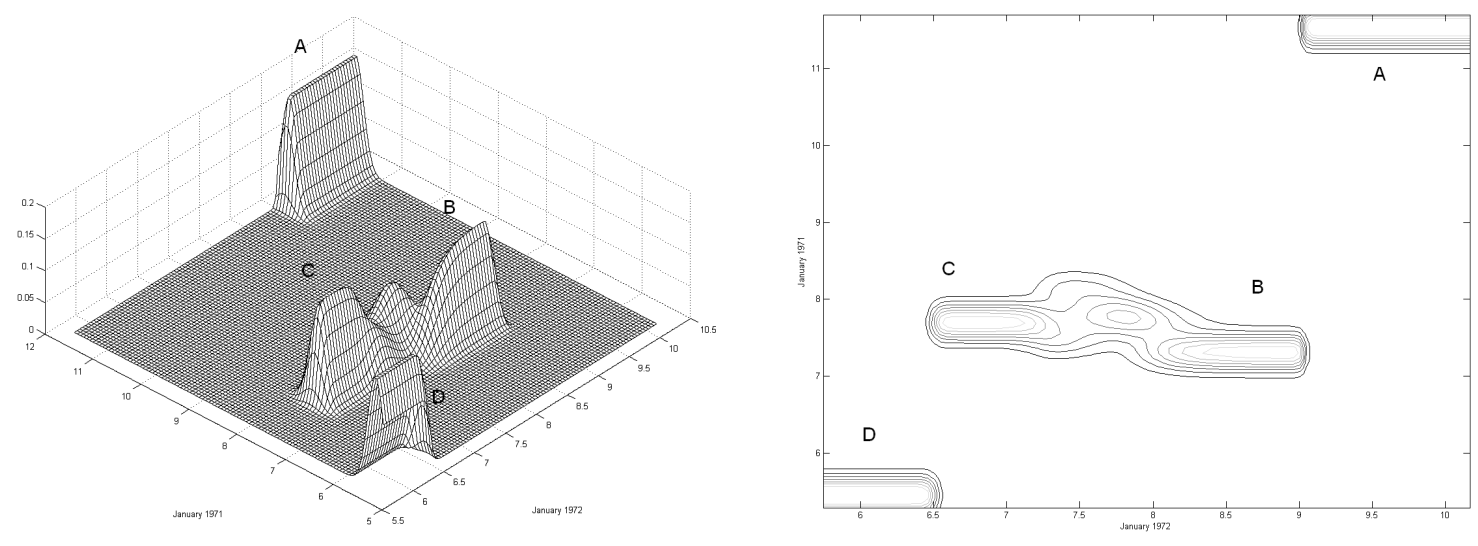
Figure 3: Stochastic Kernel-density estimate with January 1999 as final period.
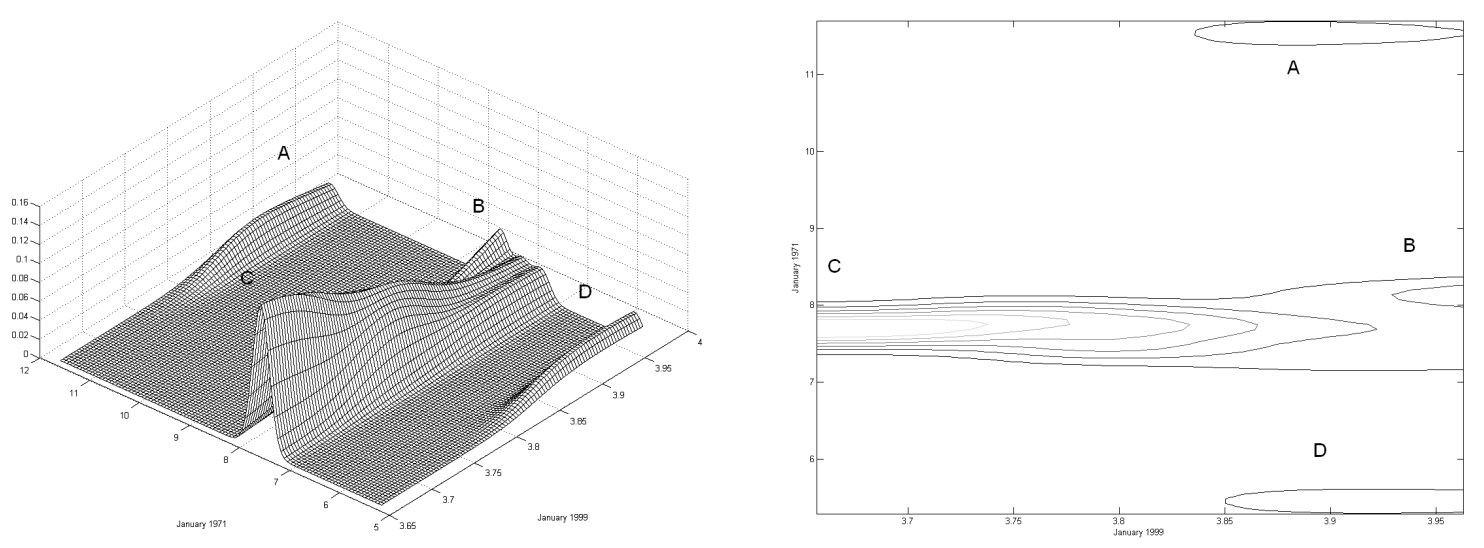
Figure 4: Transition to the year 2002.
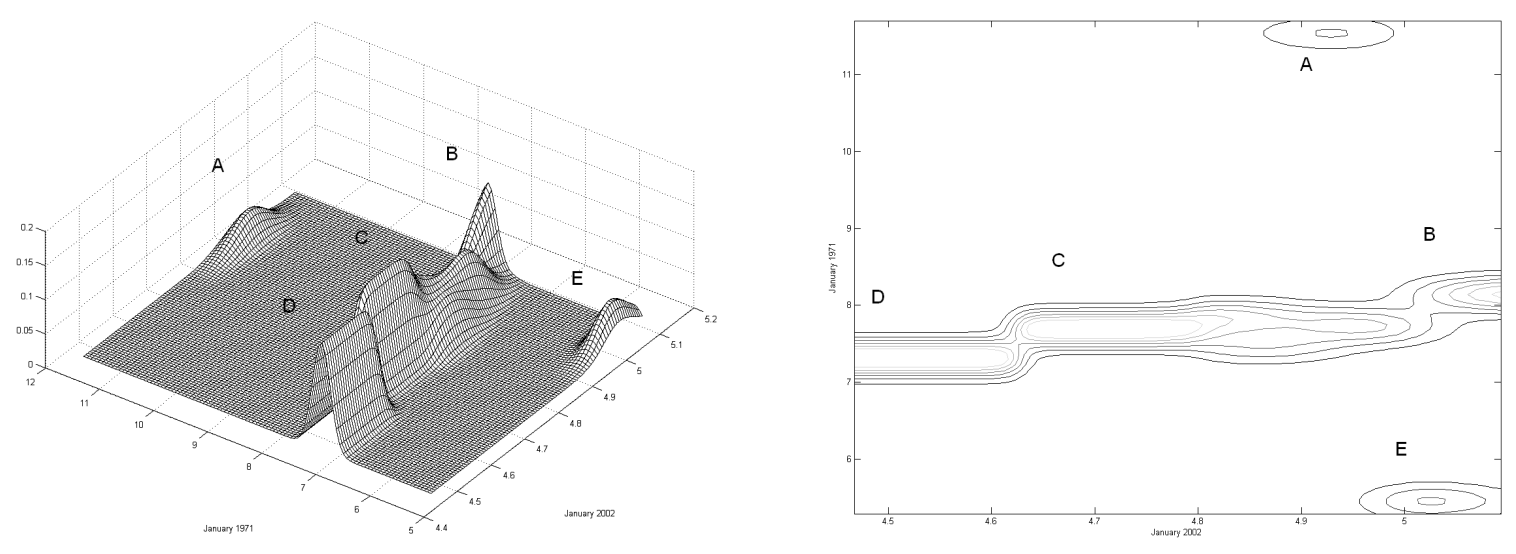
Figure 5: Transition to the present day.
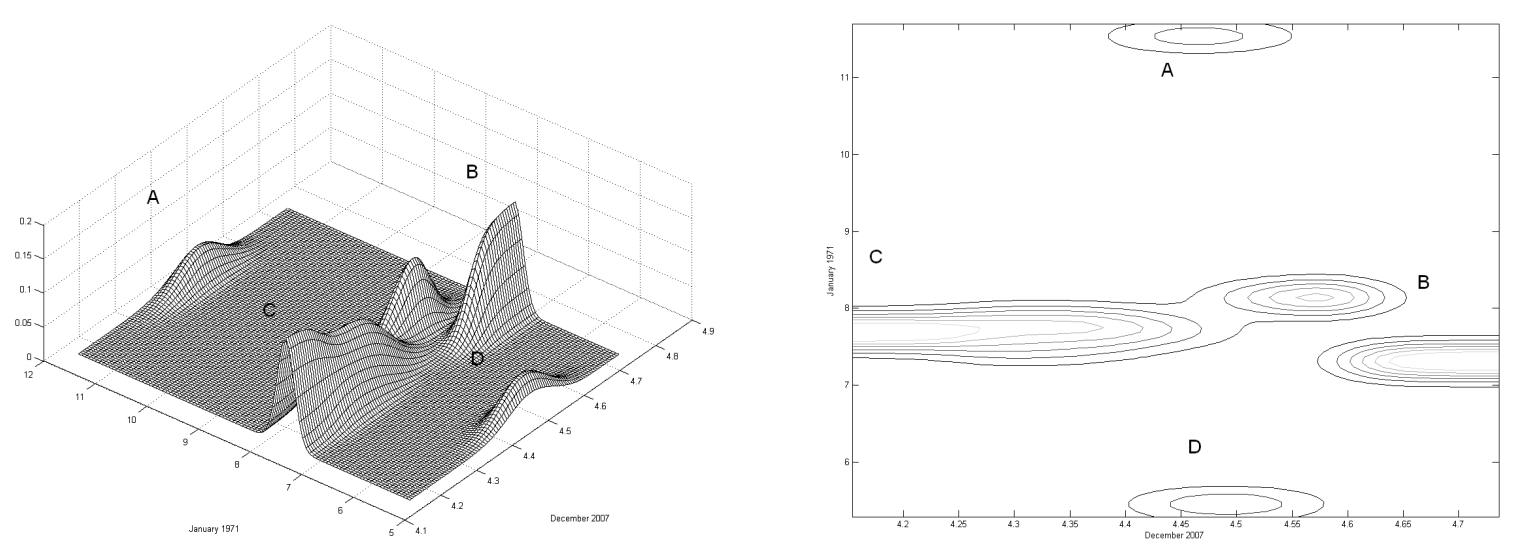
Figure 6: Ergodic distribution.

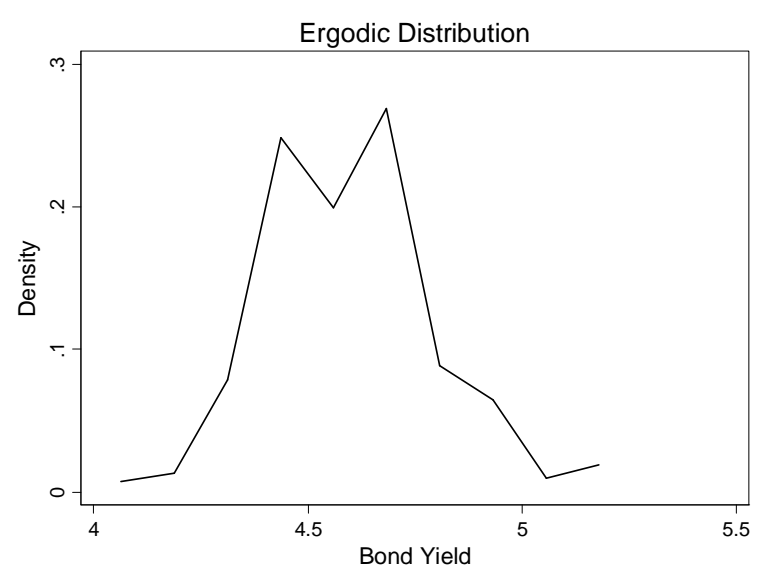


Table 1: Summary Statistics.

\begin{tabular}{c|ccccc} 
& $1971-1980$ & $1981-1990$ & $1991-1997$ & $1998-2001$ & $2002-2007$ \\
\hline Mean & 9.44 & 11.01 & 8.07 & 4.98 & 4.13 \\
Standard Deviation & 2.80 & 3.80 & 2.13 & 0.35 & 0.47 \\
Maximum & 16.84 & 21.50 & 14.54 & 5.60 & 5.04 \\
Minimum & 5.50 & 5.89 & 5.58 & 4.49 & 3.33
\end{tabular}

